\title{
How growth and location are sensitive to transport and telecommunication infrastructures?
}

\author{
Stéphane Riou* \\ Creuset, University of Saint-Etienne, France
}

\section{$1 \quad$ Introduction}

Some recent empirical works show that the convergence process of some European cohesion countries hides more regional inequalities inside each of them. Spain and Portugal have strongly converged towards the European countries but have also known an increasing phenomenon of regional inequalities (Quah (1996)). This is consistent with the results of Martin (1998) which confirm a global convergence at the countries level but suggest that regions inside them don't participate in this process. These empirical results are in sharp contrast with the sums devoted to the european regional policy. One third of the community budget was devoted to this policy for the period from 1994 to 1999. For european policy makers, the reduction in regional inequalities must promote higher growth at the national and european levels. The preceding empirical works suggest that there are not clear evidences of such positive relation between less regional inequalities and growth. Then, policy makers would face a possible dilemma between regional cohesion and national or european growth. This gives rise to two theoretical questions.

What are the economic mechanisms at the origin of such dilemma? For Kuznets (1966), the agglomeration of economic activities may be a fact linked with the economic growth. A more recent literature using both economic geography (see Krugman, (1991) and Martin and Rogers (1995)) and endogenous growth (Romer (1990) and Grossman and Helpman (1991))

* Address : Creuset, Université Jean Monnet, 6. rue basse des rives, 42023 Saint-Etienne cedex 02. e-mail : stephane.riou $\mathrm{Quniv}$-st-etienne.tr 
frameworks gives some interesting theoretical answers to this question. By using such framework with no labor migration and perfect capital mobility, Martin and Ottaviano (1999) show that an increase in industrial concentration in a region where $R \& D$ activities are performed has a positive effect on the national growth. This relation is due to perfectly localized knowledge spillovers. With this assumption, more agglomeration promotes technological interactions that reduce the cost of innovation and increase the creation of new economic activities. This relation has a strong policy implication in the european context : is public support able to make disappear this trade-off between aggregate growth and less agglomeration of economic activities?

Martin (1999) introduces the role of public infrastructures in the endogenous geography and growth model of Martin and Ottaviano (1999). In this paper, Martin (1999) shows that most of the traditional regional policies applied in Europe are faced with a trade-off between growth and the spatial distribution of economic activities. For instance, a public investment in inter-regional transport infrastructures may not lead to a lower industrial concentration in a rich region. With increasing returns and as long as this region has a larger market size, this investment will increase its attractiveness. Nevertheless, with localized knowledge spillovers, this shift in the geography has a positive effect on the growth rate. This result suggests that the european priority for inter-regional infrastructures may have a complex impact on regional development.

Our paper is an extension of Martin (1999) which stresses on the role of knowledge spillovers on the public policies results. By introducing imperfect inter-regional spillovers in $R \& D$, we ask whether a deconcentration of technological interactions may be a purpose of public policy leading to higher growth and less regional inequalities. We also analyze which investment in infrastructures should be privileged in this purpose.

Many recent empirical works suggest that knowledge spillovers are neither local nor global but are imperfectly transmitted between regions (see Eaton and Kortum (1997), Caballero and Jaffe (1993), Maurseth and Verspagen (1999)). Baldwin, Martin and Ottaviano (2001) introduces imperfect inter-regional spillovers in an economic geography and growth model with no capital mobility. The authors show that contrary to a decrease in the transport cost on goods, more flows of knowledge between regions can make a core-periphery equilibrium unstable. An increase in inter-regional spillovers creates an industrialization in the poor regions and fosters convergence in industrial geography and in incomes. Nevertheless, this convergence leads to a lower global growth rate because of the loss of intra-regional spillovers in the rich region. Contrary to Baldwin, Martin and Ottaviano (2001), we assume a perfect capital mobility and we model different infrastructures that the public policies may improve in order to facilitate inter-regional spillovers. Two different infrastructures are distinguished.

First, we assume that transport infrastructures between regions do not only affect trade in goods but also facilitate knowledge flows between 
them. Baldwin, Forslid, Martin, Ottaviano and Robert-Nicoud (2001) suggest that trades in goods and in ideas are two processes which are certainly intertwined. We propose an original modeling of this phenomenon.

Second, we link knowledge flows with telecommunication infrastructures. For Quah (2000), the expansion of these infrastructures modifies the interactions between firms by lowering the impediment of distance. These last years, various projects aiming at improving numerical networks in the poor european regions have been sustained by the European Social Fund. This proves that the European Union becomes aware of the new possibilities offered by these infrastructures. The model displays that through its impact on knowledge diffusion, an investment in inter-regional transport infrastructures can lead to a relocation of firms in the poor region. Nevertheless, this original centrifugal effect is more than offset by the traditional centripetal effect due to pecuniary externalities. In this case, the public policy increases the agglomeration of firms in the rich region and generates a positive effect on the aggregate growth. We show that only a policy which facilitates knowledge flows between regions by an improvement in telecommunication infrastructures can attain the objectives of higher growth and regional equity. Finally, we propose a welfare analysis. Because of a positive growth effect, both regions gain from more agglomeration in the rich one. Nevertheless, these gains decrease with the quality level of telecommunication infrastructures.

The general framework developed by Martin et Ottaviano (1999) is presented in the next section. Section 3 presents our assumptions concerning knowledge spillovers and we derives the equilibrium growth rate which depends on geography. Section 4 defines the steady state equilibrium. Section 5 analyzes the effects of public policies and how the welfare in each region is sensitive to geography.

\section{The model of Martin and Ottaviano (1999)}

\subsection{The general framework}

The general framework is similar to Martin and Ottaviano (1999). The model is based on two regions called $a$ and $b$. Each region is endowed with a fixed amount of labor, $L=L^{a}=L^{b}$, which has no possibilities to migrate but are mobile between sectors. Labor can be used to produce a homogeneous and numeraire good $Y$ and differentiated technological goods which are aggregated into a composite good $D$.

Call $N$ the total number of varieties available in the economy. Preferences are instantaneously Cobb-Douglas and intertemporally CES with 
unit elasticity of intertemporal substitution :

$$
U=\int_{0}^{\infty} \ln \left[D(t)^{\alpha} C_{Y}(t)^{1-\alpha}\right] e^{-\rho t} d t,
$$

where $C_{Y}$ is the individual consumption of the homogeneous good and $\rho>0$ is the rate of time preference. $\alpha \in] 0,1[$ is the share of expenditure devoted to $D$ which, following Dixit and Stiglitz (1977), consists of a number of different varieties :

$$
D(t)=\left[\int_{i=1}^{N(t)} D_{i}(t)^{\frac{\sigma-1}{\sigma}} d i\right]^{\frac{\sigma}{\sigma-1}}, \sigma>1
$$

$\sigma$ is the elasticity of substitution between varieties as well as own-price elasticity of demand for each variety. As Grossman and Helpman (1991), growth will come from an increase in the variety of goods measured by $N$.

The expenditures $E^{a}$ of a representative consumer in region $a$ are given by :

$$
E^{a}=\int_{0}^{n_{n}} p_{i}^{a} D_{i}^{a a} d i+\int_{n_{a}}^{N} \tau p_{i}^{b} D_{i}^{a b} d i+p_{y} C_{Y}^{a}
$$

$D_{i}^{a a}$ and $D_{i}^{a b}$ are demands of a consumer located in region $a$ in variety $i$ produced in $a$ and $b . p_{i}$ is the price of the $i-t h$ variety and $n^{a}\left(n^{b}\right)$ is the number of varieties produced in region $a(b)$, such that $N=n^{a}+n^{b}$.

As in Samuelson (1954) and in the new economic geography models, transport cost is modeled in the form of an iceberg cost. $\tau$ is more than 1 so that only a fraction of the good purchased is consumed.

In order to tie down the wage rate of the economy $w$, the homogeneous and numeraire good is costlessly traded. This homogeneous good is produced using only labor with constant returns to scale in a perfectly competitive sector. Without loss of generality, the input requirement is set to 1 . For convenience, the demand of this good in the whole economy is large enough that it cannot be satisfied by production in one region only. This assumption ensures that in equilibrium the homogeneous good will be produced in both regions. Hence, because of free trade and the choice of $Y$ as the numeraire, the wage rate and the price of $Y$ are equal to one everywhere.

The differentiated goods are produced in a monopolistically competitive sector. Each variety is produced with increasing returns to scale. This ensures that each firm produces only its own variety. For the production of a variety to be possible, a blueprint has to be invented first. Therefore, development of a blueprint represents a fixed cost. After registration, a patent gives an infinitely lived property right. For convenience, research is performed by firms themselves which then use the invention to start production. Furthermore, innovation and production processes can be conducted in different regions. Finally, to close the model, it is necessary to specify the institution that governs the intertemporal allocation of resources. There exists 
a financial market where a safe bond is traded and bears an interest rate $r$ in units of the numeraire. This market is global : the regional origin of the participants doesn't matter. By this market, firms finance their investment in $\mathrm{R} \& \mathrm{D}$. Therefore, the total individual income is composed of the wage rate equal to one and of the investment returns in innovation. Call $H^{a}$ and $H^{b}$, total investment endowments in region $a$ and $b$. These endowments being completely used for all $t$, we have :

$$
H^{a}+H^{b}=n^{a}+n^{b}=N
$$

For innovation to happen at all, some investment endowments $H^{a}(0)$ and $H^{b}(0)$ or blueprints $n^{a}(0), n^{b}(0)$ are assumed to be owned by consumers from the start with an inequality such that:

$$
H^{a}(0)>H^{b}(0)
$$

which implies :

$$
n^{a}(0)>n^{b}(0)
$$

This initial asymmetry will give rise to more important rents of capital in region $a$ and then, to an income and expenditure inequality between regions.

We may precise the main consequences of the capital mobility compared with the capital immobility assumption made in the endogenous growth and geography model of Baldwin, Martin and Ottaviano (2001). Because of capital mobility, profits will be repatriated in the region where capital is owned. This means that the incentives to accumulate capital will be the same in both regions and will not depend on the location of firms. With such assumption, the share of capital owned by each region is permanent and fully given by the initial distribution of capital ownership between the two regions ${ }^{1}$.

The solution of the model only requires the characterization of the steady state. Call $\gamma=\frac{n^{a}}{N} \in[0,1]$, the share of varieties or firms producing in region $a$. Therefore, $1-\gamma$ gives the share of firms locating in region $b$. At the steady state, the level of agglomeration in region $a, \gamma$, the growth rate, $g=\frac{\dot{N}}{N}$, and the expenditures $E^{a}$ and $E^{b}$ are constant. Then, we will define the equilibrium relations between these three endogenous variables.

1 With capital and labor immobility, Baldwin, Martin and Ottaviano (1999) show that the number of firms located in a region and the capital ownership in this region are strictly identical. In such case, the profits and the incentives to accumulate capital may be different between regions. Then, the initial ownership of capital may not be permanent and catastrophic agglomeration may appear (cf. Baldwin, Forslid, Martin, Ottaviano and Robert-Nicoud (2003)). 


\subsection{The equilibrium location of production}

\subsubsection{The producer equilibrium}

The supply of one unit of each variety requires $\beta$ units of labor intersectorially mobile. The profits of a typical producer are :

$$
\pi^{a, b}=p^{a, b} x^{a, b}-\beta w x^{a, b}
$$

where $w=1$ and $x^{a, b}$ is the output or size of a typical firm in equilibrium, locating its production in region $a$ or $b$. Maximization of profits implies that firms mark up price over marginal cost by a factor $\sigma /(\sigma-1)$. Therefore, optimal pricing for any variety and operating profits are :

$$
p^{a}=p^{b}=\frac{\beta \sigma}{\sigma-1}
$$

and

$$
\pi^{a, b}=\frac{\beta x^{a, b}}{\sigma-1}
$$

\subsubsection{The consumer equilibrium}

Consumers solve their maximization problem in two separate steps.

First, the static demands of a representative consumer in homogeneous and differentiated goods are derived from utility maximization (cf. (1) and (2)) subject to the budget constraint (3). For a representative consumer living in region $a$, this gives the usual following demands :

$$
\begin{aligned}
Y^{a} & =(1-\alpha) E^{a} \\
D_{i}^{a a} & =\frac{\sigma-1}{\beta \sigma} \frac{\alpha E^{a}}{n^{a}+n^{b} \delta} \\
D_{i}^{a b} & =\frac{\sigma-1}{\beta \sigma} \frac{\alpha E^{a} \tau^{-\sigma}}{n^{a}+n^{b} \delta}
\end{aligned}
$$

with $\delta=\tau^{1-\sigma}$. Following Martin and Rogers (1995) and Martin (1999), $\tau$ is related to the quality of transport infrastructures. A reduction of $\tau$ will be regarded as the consequence of a public policy improving transport infrastructures between regions. As the partial derivative of $\delta$ with $\tau$ is negative $\left(\frac{\partial \delta}{\partial \tau}<0\right)$, an increase of $\delta$ will follow such public investment.

Second, the intertemporal optimization by consumers implies that the growth rate of individual expenditures, $E^{a}$ and $E^{b}$, is equal to the difference between the interest rate and the rate of time preference ${ }^{2}$ :

$$
\frac{\dot{E}^{a}}{E^{a}}=\frac{\dot{E}^{b}}{E^{b}}=r-\rho
$$

2 For a derivation, see Grossman and Helpman (1991), chap. 3. 
We may now define the equilibrium condition for the location of production plants $\gamma$ which is derived from the market clearing conditions of the technological sector. The supply of each variety has to be equal to its demand from consumers in both regions :

$$
\begin{aligned}
& x^{a}=\frac{\alpha L(\sigma-1)}{\beta \sigma}\left(\frac{E^{a}}{N[\gamma+(1-\gamma) \delta]}+\frac{E^{b} \delta}{N[\gamma \delta+(1-\gamma)]}\right) \\
& x^{b}=\frac{\alpha L(\sigma-1)}{\beta \sigma}\left(\frac{E^{a} \delta}{N[\gamma+(1-\gamma) \delta]}+\frac{E^{b}}{N[\gamma \delta+(1-\gamma)]}\right)
\end{aligned}
$$

For constant shares of production plants $(\gamma)$ in the two regions, firms must have no incentives to relocate their production. Then, firms must be indifferent between producing in region $a$ or $b$. This happens if $\pi^{a}=\pi^{b}$ or $x^{a}=x^{b}$ (cf. (9)). With $\theta=\frac{E^{a}}{E^{a}+E^{b}}$ the share of per-capita expenditures from region $a$, this equilibrium condition implies that we can solve (14) and (15) for $\gamma$ :

$$
\gamma=\frac{\theta-(1-\theta) \delta}{(1-\delta)}
$$

Equation (16) illustrates the forward linkage at work in the model. Firms in the increasing returns sector tend to locate in the region with the highest level of per-capita expenditures. This is the traditional home market effect. The location equilibrium also depends on the quality of transport infrastructures. Through a direct effect, $\delta$ is at the origin of a pecuniary externality : the level of inter-regional infrastructures positively affects market interactions and location choices towards large markets.

Finally, optimal size of firms $(x)$ for a given level of expenditures is obtained by combining (14) and (15):

$$
x=\alpha L \frac{\sigma-1}{\beta \sigma} \frac{E^{a}+E^{b}}{N} \quad \text { with } \quad x=x^{a}=x^{b}
$$

\section{Spatial knowledge spillovers and the equilibrium growth}

\subsection{Imperfect knowledge spillovers between regions}

The innovation sector works as in Grossman and Helpman (1991 chap. 3). Innovation is a constant returns to scale activity for the individual firms but producing external increasing returns to scale. The R\&D productivity of a new lab increases with the number of production plants. Therefore, knowledge spillovers are transmitted from production to $R \& D$. Two assumptions are introduced concerning knowledge spillovers. 


\section{The spatial dimension of technological relations}

Knowledge spillovers are usually modeled as being perfectly intra or inter-regional (see Englmann and Walz (1995), Walz (1996), Martin (1999)). The assumption of intra-regional spillovers comes from the marshallian approach of knowledge diffusion (cf. Marshall (1926)). In this approach, knowledge is highly localized and is only locally transmitted to firms. Conversely, inter-regional spillovers would define some knowledge flows between regions. As in Baldwin, Martin and Ottaviano (2001) and Baldwin and Forslid (2000), we assume partially localized knowledge spillovers. Empirical studies as Eaton and Kortum (1997), Caballero and Jaffe (1993) and, more recently; Maurseth and Verspagen (1999) suggest that inter-regional spillovers are neither perfect nor nonexistent at an international or european level.

At the regional level, Feldman (1994) and Jaffe (1989) give evidences concerning intra-regional spillovers. The spatial proximity creates local interactions between firms and workers. This locally increases both spillovers and R\&D productivity. Nevertheless, in the european context, it's difficult to abstract from the implications of the integration process on knowledge flows between regions. For Baldwin and Forslid (2000), lowering the cost of trade in goods is only one aspect of regional integration which also leads to more technological relations between regions. Increasing cross-border merger and acquisition activities and business and personal travel would be another facet of a more and more integrated economy. Finally, such process would create a largely open technological environment with a declining cost of trade in ideas and less impediments for knowledge flows.

That's why Baldwin, Martin and Ottaviano (2001) or Baldwin and Forslid (2000) introduce imperfect inter-regional spillovers. Nevertheless, these models don't analyze the channels of diffusion and if a public policy should improve them. We focus on these questions by assuming that two main infrastructures may improve knowledge flows between firms located in different regions : transport and telecommunication infrastructures.

\section{Transport and telecommunication infrastructures : two channels of inter-regional spillovers}

Most of the static or dynamic economic geography models assume that an improvement in transport infrastructures only reduces the transaction cost on goods. When Baldwin, Martin and Ottaviano (2001) introduce inter-regional spillovers, they make a sharp distinction between infrastructures which facilitate trade in goods and knowledge flows between regions. Nevertheless, it is clear that some improvements in infrastructures which reduce the transaction cost in goods also reduce the transaction cost in ideas. The construction or the modernization of roads networks appears as the most evident example of this double effect. The technological and inter-regional relations between firms depends on the individual mobility because a part of the knowledge flows may concern tacit knowledge which 
is better transmitted through personal contacts. Then, some good transport infrastructures can facilitate these contacts. Therefore, we assume a positive causality relation between the quality level of transport infrastructures between regions and inter-regional knowledge flows. In this case, an improvement in transport infrastructures facilitates both market and non market interactions.

For this reason, we model the influence that transport infrastructures have on knowledge flows with the same functional form used for trade in goods :

$$
\delta=\tau^{1-\sigma}
$$

with $\tau>1, \sigma>1$ and $0<\delta<1^{3}$. Note that this functional form keeps the same properties previously defined. As the partial derivative of $\delta$ with respect to $\tau$ is negative, we will regard an increase in $\delta$ as an improvement of transport infrastructures that facilitates inter-regional spillovers. Finally, note that the parameter $\sigma$, which is the elasticity of substitution between goods, also will measure the degree of substitution between the knowledge they contain. Therefore, we assume that the higher the elasticity of substitution between goods in a given economy is, the less the knowledge used in their production process will be usable for new R\&D labs. This means that for a given level of transport infrastructures, the incentives for interregional spillovers negatively depends on this elasticity of substitution as $\delta$ is decreasing with $\sigma$.

Telecommunication infrastructures are a second important channel of knowledge diffusion. Quah (2000) argues that the new technologies of information and communication lead to new patterns relations in the knowledge exchange for which the spatial impediment is weakened, requiring few direct interactions. Cairncross (2001) offers several evidences concerning the decrease in the cost of knowledge diffusion. This author considers the development of the telecommunication infrastructures as the death of distance. It is clear that the new technologies, by giving a digitized form to knowledge, multiply the sources of information and facilitate its transmission. Therefore, an effective and competitive telecommunication system seems to be a key factor in regional economic development. Concerning digital connections which allow access to the advanced networks and to modern data transmission, a recent report of the European Commission suggests that gaps remain across Union (European Commission (1999)). We will assume that some inter-regional knowledge spillovers may be diffused by this channel, depending on its quality level on which public policy can invest for improvement. For convenience, we use the same functional form than for transport infrastructures :

$$
\lambda=\tau_{\text {tel }}^{1-\sigma}
$$

3 Note that the parameter $\delta=\tau^{1-\sigma}$ is a particular formulation of the iceberg cost derived from the demand functions. The iceberg cost implies that when an unit of good is traded, only a share $\frac{1}{\tau}$ is consumed. The same definition may be applied for knowledge : if each production plant represents a potential spillover for R\&D labs, only a share $\frac{1}{\tau}$ will be really transmitted if the spillover is inter-regional. 
with $\tau_{\text {tel }}>1, \sigma>1$ and $0<\lambda<1$. The parameter $\tau_{\text {tel }}$ may be viewed as an iceberg cost on knowledge flows diffused by telecommunications. This cost depending on the quality level of the telecommunication, we will regard an increase in $\lambda$ (or decrease in $\tau_{t e l}$ ) as an improvement of telecommunication infrastructures between regions. As in the case of transport infrastructures, the incentives to transmit knowledge through telecommunication is weighted by the elasticity of substitution between goods $\sigma$.

Finally, we make the assumption that knowledge spillovers between regions depend on the average quality of inter-regional infrastructures of telecommunication and transport. New information and communication technologies are not pure substitutes of transport infrastructures. Some knowledge can be digitized and supplied from a distance, but most cannot and needs infrastructures which facilitate face-to-face and personal contacts (Venables (2001), Gaspar and Glaeser (1998)). Then, both infrastructures must be taken into account. The channels of inter-regional spillovers are defined by the following variable:

$$
\Omega=\frac{\delta+\lambda}{2}
$$

with $0<\delta, \lambda<1$.

\subsection{The equilibrium location of innovation and growth rate}

Now, we must define how $R \& D$ labs are located and how the growth rate of the economy is obtained.

The $R \& D$ sector is defined with the following innovation production functions :

$$
\dot{n}^{a}=\eta L_{l}^{a} N(\gamma+\Omega(1-\gamma))
$$

if $\mathrm{R} \& \mathrm{D}$ labs locate in region $a$, and

$$
\dot{n}^{b}=\eta L_{I}^{b} N((1-\gamma)+\Omega \gamma)
$$

if $\mathrm{R} \& \mathrm{D}$ labs locate in region $b . L_{I}$ is labor employed in $\mathrm{R} \& \mathrm{D}$ and $\eta$ is a productivity parameter.

With perfect capital mobility, R\&D labs locate in both regions only if the cost to engage capital in $R \& D$ investment is geographically the same. With imperfect inter-regional knowledge spillovers $(0<\Omega<1)$ and $w=1$ in both regions, it is less costly to invest in the region with the highest number of production plants. As $H^{a}(0)>H^{b}(0)$, pure rents induced by investment in innovation are higher in region $a$ for all $t$. Therefore, region $a$ has the highest level of incomes and expenditures $\left(\theta>\frac{1}{2}\right)$ and more firms are located in this region in equilibrium :

$$
\gamma>\frac{1}{2} \quad \forall t
$$


For this reason, the R\&D sector will only be active in region $a$. It is also the region where the aggregate growth of the economy will be determined.

The equilibrium growth rate is derived from the incentives to innovate. This requires the traditional condition of no arbitrage opportunity between investing in $\mathrm{R} \& \mathrm{D}$ and borrowing at the safe rate $r$. Call $v(t)$ the stock market value of a firm equaling the present discounted value of its profit. That is,

$$
v(t)=\int_{t}^{\infty} e^{-r(s-t)} \frac{\beta x(s)}{\sigma-1} d s
$$

where $r(t)$ represents the cumulative discount factor applicable to profits earned at time $t$. Differentiating (20) with respect to time gives us the no arbitrage condition which has to hold at every moment in time in order to ensure capital-market equilibrium:

$$
\dot{v}+\frac{\beta x}{\sigma-1}=r v
$$

With free entry and zero profits in the $R \& D$ sector, the value of a firm is equal to the marginal cost of innovation $c$ in the equilibrium. With $w=1$, this leads to the following equality :

$$
c=v=\frac{\eta}{N\left[\gamma+\frac{\delta+\lambda}{2}(1-\gamma)\right]}
$$

At a steady state, $\gamma$ is constant. This means that $n^{a}, n^{b}$ and $N$ will grow at the same constant rate $g=\frac{\dot{N}}{N}$. Therefore, $c$ and $v$ will decrease at the same rate:

$$
\frac{\dot{v}}{v}=\frac{\dot{c}}{c}=-g
$$

Because also consumers expenditures are constant in steady state, the interest rate $r$ is equal to the rate of time preference $\rho$ (see Eq. (13)). With equations (21) and (22), the arbitrage condition is now :

$$
g+\rho=\frac{\beta x}{\sigma-1}\left(\frac{n^{a}+\frac{\delta+\lambda}{2} n^{b}}{\eta}\right)
$$

Consider now the market clearing condition for labor. The labor cmployed in $\mathrm{R} \& \mathrm{D}\left(L_{I}\right)$ in the economy depends on the aggregate growth rate:

$$
L_{J}=\frac{\eta \dot{N}}{N\left[\gamma+\frac{\delta+\lambda}{2}(1-\gamma)\right]}=\frac{\eta g}{\gamma+\frac{\delta+\lambda}{2}(1-\gamma)}
$$


With total demand in differentiated and homogeneous goods, the labor market equilibrium is :

$$
2 L=\frac{\eta g}{\gamma+\frac{\delta+\lambda}{2}(1-\gamma)}+\frac{\sigma-\alpha}{\sigma} L\left(E^{a}+E^{b}\right)
$$

Substituting the optimal size of firms (17) in (24) and with (26), we find the following growth rate:

$$
g=\frac{2 L \alpha}{\eta \sigma}\left[\gamma+\frac{\delta+\lambda}{2}(1-\gamma)\right]-\left(\frac{\sigma-\alpha}{\sigma}\right) \rho
$$

The aggregate growth rate is sensitive to the location equilibrium of the production plants $(\gamma)$. Contrary to Martin and Ottaviano (1999) and Martin (1999) who assume perfectly localized spillovers, the aggregate growth also depends on firms located in region $b$. Nevertheless, as interregional spillovers are imperfectly transmitted, the growth rate is more sensitive to the spatial concentration in region $a$ where $R \& D$ labs are located. Note also that for a given location equilibrium an increase in inter-regional infrastructures has a positive effect on growth.

\section{Income inequality and steady state equilibrium}

\subsection{Income inequality and growth}

The steady state of the model can be found by defining a last equilibrium relation. We have already defined how the equilibrium location of firms $\gamma$ is determined by the expenditure inequality $\theta$ (Eq. (16)) and how the equilibrium growth rate $g$ depends on $\gamma$ (Eq. (27)). The last relation consists in defining the income and expenditure inequality as a function of $g$.

In both regions, optimizing consumers set their expenditures at a permanent income hypothesis level in steady state. Then, they will consume their labor income, equals to 1 in both regions, and $\rho$ times the value of the initial per-capita stock of blueprints as only the profits of this initial stock are pure rents. We get the following expressions for region $a$ and region $b$ :

$$
\begin{aligned}
& E^{a}=1+\frac{\rho v H^{a}(0)}{L} \\
& E^{b}=1+\frac{\rho v H^{b}(0)}{L}
\end{aligned}
$$

With equations (21) and (23), the market value of a firm in the equilibrium is :

$$
v=\frac{\pi}{\rho+g}
$$


where $v$ is a decreasing function of the growth rate $g$. This is a classical relation in endogenous growth models like Grossman and Helpman (1991). An increase in the growth rate means that more firms enter the market. The future profits decreasing, this also deteriorates the market value of capital.

Call $h=\frac{H^{a}}{N}$ the share of capital owned by region $a$. Because of free capital mobility, remember that this share will be constant through time and fully given by the initial regional endowments $H^{a}(0)$ and $H^{b}(0)$. Inserting the equilibrium profits in (29) and combining the resulting equation with (28a) and (28b), we get the consumers' share of expenditures and income in region $a$ :

$$
\theta=\frac{1}{2} \frac{\sigma(g+\rho)+\alpha \rho(2 h-1)}{\sigma(g+\rho)}
$$

As $H^{a}(0)>H^{b}(0)$ and the capital is mobile and grows at the same rate in both regions, we know that $h>\frac{1}{2}$. With Eq. (30), we can observe that this inequality in the capital endowments leads to an income and expenditures inequality as $\theta>\frac{1}{2}$ with $h>\frac{1}{2}$.

Note also that the income and expenditures gap is decreasing in $g$. We know that, through a competition effect, an increase in the growth rate lowers the capital rent. As the capital rent is a more important part of the total income in region $a$ than in region $b$, residents in region $a$ will be more sensitive to this income loss. For this reason, the income inequality between regions decreases with higher growth. This means that the variables at the origin of the aggregate growth, including transport and telecommunication infrastructures, may have a positive effect on the reduction of income inequality.

\subsection{The steady state equilibrium}

Now we close the model by defining the equilibrium location of firms and the growth rate at the steady state. Inserting the growth rate equation in (30), we get:

$$
\theta=\frac{L\left[\gamma+\frac{\delta+\lambda}{2}(1-\gamma)\right]+\rho \eta h}{2 L\left[\gamma+\frac{\delta+\lambda}{2}(1-\gamma)\right]+\rho \eta}
$$

Then, inserting the preceding expression in (16), we find the following equation :

$$
\gamma=\frac{(1-\delta)\left(L\left(\gamma+\frac{\delta+\lambda}{2}(1-\gamma)\right)\right)+\rho \eta((1+\delta) h-\delta)}{\left(2 L\left(\gamma+\frac{\delta+\lambda}{2}(1-\gamma)\right)+\rho \eta\right)(1-\delta)}
$$

where $\gamma$ is solution of the following quadratic function :

$$
\gamma^{2}(L(1-\delta)(2-(\lambda+\delta)))+\gamma\left((1-\delta)\left(L\left((\delta+\lambda)+\frac{\delta+\lambda}{2}-1\right)+\rho \eta\right)\right)
$$




$$
+\left(-(1-\delta) L\left(\frac{\lambda+\delta}{2}\right)-\rho \eta((1+\delta) h-\delta)\right)=0
$$

which admits two roots : one is positive, the other is negative. The positive one gives the location equilibrium at the steady state:

$$
\gamma=\frac{-(1-\delta)(A+\rho \eta)+\sqrt{(1-\delta)^{2}(A+\rho \eta)^{2}-4 L B C}}{2 L B}
$$

with $A=L\left((\delta+\lambda)+\frac{\delta+\lambda}{2}-1\right), B=(1-\delta)(2-(\lambda+\delta))$ and $C=\left(-(1-\delta) L\left(\frac{\lambda+\delta}{2}\right)-\rho \eta((1+\delta) h-\delta)\right)$. The equilibrium value of $g$ at the steady state follows by inserting Eq. (33) in Eq. (27).

\section{$5 \quad$ Regional policies and welfare analysis}

As in Martin (1999), we focus now on policies improving infrastructures and their effects on firms location $\gamma$, on the geography of incomes and expenditures $\theta$ and on the aggregate growth rate $g$. In addition, we study whether the agglomeration of firms in the market equilibrium $(\gamma)$ is efficient from a welfare point of view for the economy as a whole when knowledge spillovers are not perfectly localized. We also ask whether the welfare gains or losses from a marginal change in economic geography are sensitive to the quality of telecommunication infrastructures.

\subsection{Public policies, regional equity and aggregate growth}

Assuming perfectly localized spillovers, Martin (1999) displays how most of the public policies on infrastructures used in Europe face a policy tradeoff between regional equity and growth. For instance, the improvement of transport infrastructures between regions leads to higher growth and lower income inequality but reinforces industrial concentration in the rich region. Nevertheless, the fact that knowledge spillovers are perfectly localized does not allow for an analysis on how a decreasing cost of trading ideas between regions may change this trade-off. With no capital mobility, Baldwin, Martin and Ottaviano (2001) show that the inter-regional knowledge diffusion has important effects on the geography of industry and on global growth. In this model, a decrease in the cost of trading ideas promotes industrialization in the poor region because of a better access to knowledge located in the rich one. Nevertheless, this leads to a lower global growth. Contrary to our specification, the authors do not distinguish between different channels of diffusion and do not focus on the way public policies may improve them.

We can give intuitions concerning the impacts that an infrastructure policy will have on industrial concentration. 
First, suppose that a policy improves telecommunication infrastructures. The effect is easily observed. According to the growth rate equation (Eq. (27)), this policy helps knowledge diffusion from firms located in region $b$ to $\mathrm{R} \& \mathrm{D}$ labs in region $a$. This leads to higher growth rate and lower capital rents which reduce the share of income in region $a(\mathrm{Eq} .(30))$. Finally, the lower differential between the size of the regional markets implies firms' relocation to region $b$ and a spatial deconcentration (Eq. (16)).

Second, an improvement in transport infrastructures has more ambiguous effects. This comes from the fact that in our specification, transport infrastructures facilitate both market and non market interactions between regions. Depending on which type of interactions is facilitated, this public policy will have opposite effects on the geography of industry :

- the first effect is well known and comes from the fact that this policy improves inter-regional trade in goods. It makes easier for firms in the rich region to supply the poor one by trade. Then, because of increasing returns, it increases the attractiveness of the rich region. The sign of the partial derivative of $\gamma$ with respect to $\delta$ (cf. Eq. (16)) for a given income inequality confirms this intuition:

$$
\frac{\partial \gamma}{\partial \delta}=\frac{2 \theta-1}{(1-\delta)^{2}}
$$

The sign is positive as long as region $a$ has a larger market size than region $b(\theta>1 / 2)$.

- the second effect comes from the more important knowledge spillovers diffused with transport infrastructures. As for telecommunication infrastructures, the public policy strengthens knowledge flows and then, increases the global growth rate. This reduces the income differential between regions and attracts firms in the poor one.

These two opposite effects work in the steady state equilibrium. If the centripetal "home market" effect is higher, the public policy will have a positive growth effect. If the centrifugal effect, through inter-regional spillovers, is dominant, the impact on growth is ambiguous. While more inter-regional spillovers will be favorable to growth, less industrial agglomeration deprives R\&D labs of local spillovers.

The net effects of an improvement in transport infrastructures both on growth and on industrial agglomeration are given in the following proposition :

Proposition 1 Even if a policy improving inter-regional transport infrastructures can generate a centrifugal force through non market interactions, the net effect is an increase in industrial agglomeration (i) and a higher growth rate (ii).

Proof 1 (see Appendix A).

Proposition 1 gives the simultaneous effects of a transport policy on growth and location. The centrifugal effect coming from better inter-regional 
spillovers does not offset the home market effect. Note that the higher growth has two origins. First, the increasing concentration in region $a$ leads to more local spillovers for R\&D labs which locate there. Second, interregional spillovers are better transmitted after the transport infrastructure policy.

As the growth rate increases, more firms enter the market and, through a competition effect, the capital income is reduced. Region $a$ being more dependent on the capital income, nominal income disparity between regions is also reduced. Martin (1999) shows that the net effect of this policy on real income inequality is more complex because of its impact on the price index in the two regions ${ }^{4}$. If nominal income disparity is reduced, the index price in region $a$ decreases as less of the goods have to be imported and the transport cost on each of them is lower. In region $b$, more agglomeration in the other region implies that a more important number of goods have to be imported but for a lower transport cost. Then, as shown in Martin (1999) and Martin and Ottaviano (1999), the relative price index changes in favor of the rich region $\left(\partial\left(P^{a} / P^{b}\right) / \partial \delta<0\right)$, but if the transport cost is already low, the effect on price indices is not sufficiently important for offset the reduction of nominal income disparity. In this case, the public policy on transport infrastructures will also imply a decrease in real income inequality.

Finally, we can give intuitions concerning the effect of financing this public policy. If the improvement is paid by a third party, it will not modify the preceding results. Nevertheless, if the infrastructures are paid by the rich region, this may lead to an income effect reinforcing the centrifugal effect from inter-regional spillovers. Then, the increase in industrial agglomeration may be reversed. This would have very ambiguous effects on aggregate growth because this would induce less intra-regional spillovers in the rich region but inter-regional spillovers would be more important and better transmitted.

Suppose now that the public policy improves the telecommunication infrastructures. Contrary to a decrease in inter-regional transport cost, such policy has no direct impact on market interactions, but only facilitates knowledge flows between regions. For this reason, the following proposition suggests that this public policy can attain both objectives of regional equity and higher aggregate growth :

Proposition 2 A regional policy improving telecommunication infrastructures reduces industrial agglomeration (i) and leads to higher growth rate (ii).

\section{Proof 2 (Appendix A)}

The first part of the proposition confirms that a better access for $\mathrm{R} \& \mathrm{D}$ labs to knowledge located in the poor region may decrease industrial

4 The price index in each region is given by the following functions: $P^{n}=(\beta \sigma / \sigma-1) N^{1 /(1-\sigma)}(\gamma+\delta(1-\gamma))^{1 /(1-\sigma)}, P^{b}=(\beta \sigma / \sigma-1) N^{1 /(1-\sigma)}(\gamma \delta+(1-\gamma))^{1 /(1-\sigma)}$ 
agglomeration. As the cost of innovation decreases, more firms enter the market. This reduces income of capital and as the rich region is more sensitive to this reduction, the nominal income inequality is less important after the public policy. Moreover, the second part of the proposition suggest that the net effect on growth is positive. The endogenous reduction of spatial concentration which implies a loss of intra-regional spillovers is more than offset by the exogenous decrease in the cost of innovation induced by the improvement in telecommunication infrastructures.

Note that real income inequality is reduced as nominal inequality is lower and the price index in region $a$ is higher but decreases in region $b$ because more of the goods are locally produced.

If the rich region finances the public policy, it will strengthen the relocation of firms in the poor one. As long as the positive growth effect induced by better telecommunication infrastructures dominates the negative effect of such relocation, the net impact on growth will be positive.

\subsection{Welfare analysis}

Many distortions at work in the model suggest that the spatial concentration in the market equilibrium is not the optimal one. A first group of standard distortions pertain to the models with monopolistic competition and horizontal product innovation (Grossman and Helpman (1991)). We are more interested in a second group of distortions inherent to the firm location choices.

First, because inter-regional spillovers are imperfectly transmitted, an increase in $\gamma$ will always increase the growth rate in the economy. Firms do not acknowledge this positive externalities. For this reason, the spatial concentration at the market equilibrium is too low. This growth effect indicates that a planner may improve a part of the welfare in both regions by increasing the spatial concentration in the rich region (region a). Nevertheless, such relocation of firms will have others welfare impacts for region $a$ and region $b$. On the one hand, when capital flows increase agglomeration of firms, more local spillovers are produced in region $a$. This in turn reduces the nominal wealth by reducing the cost of innovation and the value of the capital (wealth effect). If a larger initial stock of capital is allocated to region $a$, this region will have a larger loss than region $b$. On the other hand, we have already noted that new locations of firms in a region create a transport cost effect. The consumers in this region save the transport cost on the new goods produced locally. This increases their real wealth. But such relocations decrease the real wealth in the region of origin since local consumers now have to pay the transport cost on a larger number of goods. These three effects can be formally defined by calculating (1) in steady state. Then, we can write the indirect utility of a representative consumer in region $a$ and 
region $b$ as a function of $\gamma$. We get the following expressions :

$$
\begin{gathered}
V_{a}=\frac{1}{\rho}\left(\ln \alpha^{\alpha}(1-\alpha)^{1-\alpha}\left(1+\frac{\rho \eta h}{\left(\gamma+\frac{\lambda+\delta}{2}(1-\gamma)\right) L}\right)\left(\frac{\sigma-1}{\beta \sigma}\right)^{\alpha}\right. \\
\times N_{0}^{\frac{\alpha}{\sigma-1}}((1-\delta) \gamma+\delta)^{\frac{\alpha}{\sigma-1}} e^{\left.\frac{\alpha g}{(\rho(\sigma-1))}\right)} \\
V_{b}=\frac{1}{\rho} \ln \alpha^{\alpha}(1-\alpha)^{1-\alpha}\left(1+\frac{\rho \eta(1-h)}{\left(\gamma+\frac{\lambda+\delta}{2}(1-\gamma)\right) L}\right)\left(\frac{\sigma-1}{\beta \sigma}\right)^{\alpha} \\
\times N_{0}^{\frac{\alpha}{\sigma-1}}(1-(1-\delta) \gamma)^{\frac{\alpha}{\sigma-1}} e^{\frac{\alpha g}{(\rho-1))}}
\end{gathered}
$$

where $g$ is the steady state growth rate given by (27). Differentiating expressions (34) and (35) with respect to $\gamma$, we obtain the welfare impact in both regions of an increase in agglomeration of firms in region $a$ :

$$
\begin{aligned}
\frac{\partial V_{a}}{\partial \gamma}= & \frac{\alpha^{2} L(2-\lambda-\delta)}{\rho^{2} \eta \sigma(\sigma-1)}+\frac{2(2-\lambda-\delta) \eta h}{(L((\lambda+\delta)(1-\gamma)+2 \gamma)+2 \rho \eta h)((\lambda+\delta)(\gamma-1)-2 \gamma)} \\
& +\frac{\alpha}{\rho(\sigma-1)} \frac{(1-\delta)}{(1-\delta) \gamma+\delta} \\
\frac{\partial V_{b}}{\partial \gamma}= & \frac{\alpha^{2} L(2-\lambda-\delta)}{\rho^{2} \eta \sigma(\sigma-1)}+\frac{2(2-\lambda-\delta) \eta(1-h)}{(L((\lambda+\delta)(1-\gamma)+2 \gamma)+2 \rho \eta(1-h))((\lambda+\delta)(\gamma-1)-2 \gamma)} \\
& -\frac{\alpha}{\rho(\sigma-1)} \frac{(1-\delta)}{(1-\gamma(1-\delta))}
\end{aligned}
$$

The three terms on the right hand side of (36) and (37) are, respectively, the growth, wealth and transport cost effects. The first common term is the positive impact on the growth rate of an increase of $\gamma$. The second element is negative in both expressions and represents the welfare loss due to the higher growth rate lowering the value of capital owned by residents. The third term represents the transport cost effect. This effect has the expected signs since it is positive for region $a$ and negative for region $b$. We can now establish the desirability of the market determined geography in terms of regional welfare. Then, we have to sign (36) and (37) at the market equilibrium given in (33). The resulting expressions being too complex for analytical results, we present numerical examples summarized in Table 1 (see Appendix B). The first row gives a benchmark case with numerical values already used in Martin and Ottaviano (1999) with perfectly localized spillovers. For this case, both regions would gain from a marginal increase in spatial concentration in region $a$ with respect to the market outcome. The other rows show that more concentration in the rich region (region $a$ ) improves the welfare in the poor region (region $b$ ) when the negative wealth and transport cost effects are offset by the positive growth effect. As in 
Martin and Ottaviano (1999), this is the case when the elasticity of substitution between goods $\sigma$ is low, the share of differentiated goods consumed $\alpha$ is high or the global market $L$ is large. Furthermore, low transport costs $\tau$ also promotes a gain in the poor region from more concentration in the rich one. For low transport costs, the relocation of firms to the rich region does not deteriorate too much the welfare in the poor one, contrary to a case with a high transport cost.

More interestingly, the first and fifth rows in Table 1 show how the welfare gain from more agglomeration in each region is sensitive to the quality of telecommunication infrastructures. For poor infrastructures $\left(\tau_{\text {tel }}=1.6\right)$, higher welfare gains are derived from an increase in $\gamma$ than for a better quality level $\left(\tau_{t e l}=1.2\right)$. The Figure 1 , which plots equations (36) and (37) for the benchmark case with respect to $\tau_{t e l}$, confirms this result. The welfare gains in both regions decline with an increasing quality level of telecommunication infrastructures $\left(\tau_{t e l} \longrightarrow 1\right)$. Finally, when telecommunications are nearly perfect, more agglomeration in region $a$ leads to a loss of welfare in region $b$.

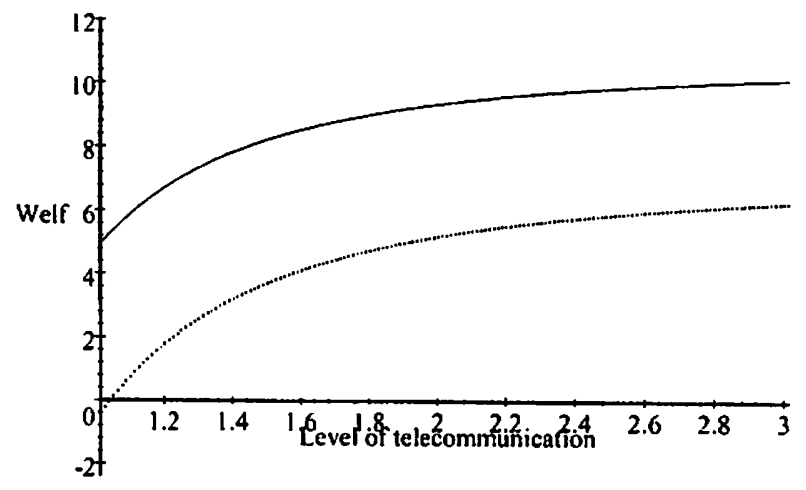

Figure 1 : Telecommunication infrastructures and welfare

\begin{tabular}{|l|l|}
\hline Solid line & Region $a$ \\
\hline Points & Region $b$ \\
\hline
\end{tabular}

This shows that the desirability of more spatial concentration highly depends on the efficiency of the channels of knowledge diffusion. When telecommunications between regions are efficient, technological knowledge is easily diffused from region $b$ to region $a$. In this case, the relocation of firms to the rich region leads to a limited gain in terms of spillovers and growth effect. Conversely, a poor infrastructure is an impediment to inter-regional spillovers. In this case, the growth is mainly produced by local spillovers in region $a$. For this reason, through the growth effect, the residents in both regions benefit more from more agglomeration in region $a$. 


\section{Conclusion}

In this paper, we propose an extension of the model of growth, geography and public policies of Martin (1999). We introduce imperfect knowledge spillovers between regions and infrastructures which facilitate their diffusion. Hence, we model some improvements in transport infrastructures which are conducive to lower trade costs and a better knowledge diffusion. Through its impact on knowledge spillovers, an investment in inter-regional transport infrastructures can lead to a relocation of firms in the poor region. Nevertheless, the traditional centripetal effect coming from market interactions always generates more spatial concentration. Even if this agglomeration effect increases growth, this confirms the result of Martin (1999) : an investment in transport infrastructures may not attain both the objectives of higher growth and less regional disparities. We show that an improvement in telecommunication infrastructures doesn't lead to this trade-off. Such investment generates higher growth and more even spatial distribution of economic activities. This policy has the same desired effects than the decrease in the cost of innovation suggested by Martin (1999). Finally, we have presented a welfare analysis. A more concentrated economic geography is not always detrimental to immobile workers in the poor region because of a positive growth effect. Nevertheless, we have shown that the gains from more agglomeration decrease with the quality level of telecommunication infrastructures.

The main point in this paper is to suggest that the various functions of infrastructures should be taken into account by policy makers. A public investment in roads or railways networks has not only an impact on trade in goods but also on trade in ideas. Most of the time, the economic geography models do not consider the second effect, while it may have implications on the geography of economic activities. This question calls for an additional research. For simplification in the model presented here, the same functional form is used to define the effect of transport infrastructures on knowledge flows and trade in goods. In another recent paper, we make the $\mathrm{R} \& \mathrm{D}$ sector more complicated by distinguishing between the elasticity of substitution between goods and the elasticity of substitution between ideas (Riou (2002)). Hence, we show that when ideas are very complementary, an improvement in transport infrastructures leads to a strong centrifugal effect which can more than compensates the centripetal effect coming from market interactions. 


\section{Appendix A}

\section{Proof 1}

(i) The first part of the proof consists in showing that a marginal improvement in transport infrastructures increases the industrial agglomeration in region $a$. Then, we search for the sign of the partial derivative of $\gamma$ with respect to $\delta$ for a given inequality in capital endowment between regions $\left(h>\frac{1}{2}\right)$.

The location equilibrium is given by :

$$
\gamma=\frac{\theta-(1-\theta) \delta}{(1-\delta)}
$$

with :

$$
\theta=\frac{\left[\gamma+\frac{\delta+\lambda}{2}(1-\gamma)\right] L+\rho \eta h}{2\left[\gamma+\frac{\delta+\lambda}{2}(1-\gamma)\right] L+\rho \eta}
$$

The partial derivatives of these two preceding equations with respect to $\delta$ are :

$$
\frac{\partial \gamma}{\partial \delta}=\frac{\left(1-\delta^{2}\right) \frac{\partial \theta}{\partial \delta}-1+2 \theta}{(1-\delta)^{2}}
$$

and

$$
\frac{\partial \theta}{\partial \delta}=\frac{\rho \eta(1-2 h)\left(L\left(\left(1-\frac{\delta+\lambda}{2}\right) \frac{\partial \gamma}{\partial \delta}+\frac{1}{2}(1-\gamma)\right)\right)}{\left(2 L\left(\gamma+\frac{\delta+\lambda}{2}(1-\gamma)\right)+\rho \eta\right)^{2}}
$$
obtain :

After insertion of $\frac{\partial \theta}{\partial \delta}$ in $\frac{\partial \gamma}{\partial \delta}$, we isolate $\frac{\partial \gamma}{\partial \delta}$. After simplifications, we

$$
\frac{\partial \gamma}{\partial \delta}=\frac{L \frac{1}{2}(1-\gamma)\left(1-\delta^{2}\right) \rho \eta(1-2 h)+\rho \eta(2 h-1)\left(2 L\left(\gamma+\frac{\delta+\lambda}{2}(1-\gamma)\right)+\rho \eta\right)}{\left(2 L\left(\gamma+\frac{\delta+\lambda}{2}(1-\gamma)\right)+\rho \eta\right)^{2}(1-\delta)^{2}-\left(1-\delta^{2}\right) L\left(1-\frac{\delta+\lambda}{2}\right) \rho \eta(1-2 h)}
$$

Denominator of $\frac{\partial \gamma}{\partial \delta}$ is positive for all $h>\frac{1}{2}$.

As $\rho \eta(2 h-1)>0$ and $\rho \eta(1-2 h)<0$, a condition for $\frac{\partial \gamma}{\partial \delta}>0$ is :

$$
1-\gamma<4 \gamma
$$

This is always verified for all $\gamma>\frac{1}{2}$.

(ii) Second, we prove that $\frac{\partial g}{\partial \delta}>0$.

As $\operatorname{sign} \frac{\partial g}{\partial \delta} \Longleftrightarrow \operatorname{sign} \frac{\partial\left(\gamma+\frac{\delta+\lambda}{2}(1-\gamma)\right)}{\partial \delta}$, we obtain :

$$
\operatorname{sign} \frac{\partial g}{\partial \delta} \Leftrightarrow \operatorname{sign}\left[\left(1-\frac{\delta+\lambda}{2}\right) \frac{\partial \gamma}{\partial \delta}+\frac{1}{2}(1-\gamma)\right]
$$


As $\frac{\partial \gamma}{\partial \delta}>0$ and $\frac{\lambda+\delta}{2}<1$ for all $\left.\delta, \lambda \in\right] 0,1[$, we verify that :

$$
\frac{\partial g}{\partial \delta}>0
$$

व

\section{Proof 2}

(i) We search now for the sign of the partial derivative of $\gamma$ with respect to $\lambda$ and for $h>\frac{1}{2}$. As in the preceding proof, we insert $\frac{\partial \theta}{\partial \lambda}$ in $\frac{\partial \gamma}{\partial \lambda}$. After simplifications, we get :

$$
\frac{\partial \gamma}{\partial \lambda}=\frac{\rho \eta(1-2 h)(1+\delta)(1-\gamma) \frac{L}{2}}{(1-\delta)\left(2 L\left(\gamma+\frac{\delta+\lambda}{2}(1-\gamma)\right)+\rho \eta\right)^{2}-(1+\delta) \rho \eta(1-2 h)\left(1-\frac{\delta+\lambda}{2}\right) L}
$$

With $h>\frac{1}{2}$, the numerator is negative. Then, for $\frac{\partial \gamma}{\partial \lambda}<0$, the denominator must be positive. This is the case as long as $h>\frac{1}{2}$ and the inter-regional spillovers are imperfect, that is $\frac{\delta+\lambda}{2}<1$.

(ii) Second, we demonstrate that $\frac{\partial g}{\partial \lambda}>0$.

As $\operatorname{sign} \frac{\partial g}{\partial \lambda} \Longleftrightarrow \operatorname{sign} \frac{\partial\left(\gamma+\frac{\delta+\lambda}{2}(1-\gamma)\right)}{\partial \lambda}$, we get :

$$
\operatorname{sign} \frac{\partial g}{\partial \lambda} \Longleftrightarrow \operatorname{sign}\left(\left(1-\frac{\delta+\lambda}{2}\right) \frac{\partial \gamma}{\partial \lambda}+\frac{1}{2}(1-\gamma)\right)
$$

After substitution of the partial derivative of $\gamma$ with respect to $\lambda$, obtained in the first part of the proof, we get :

$$
\frac{\partial g}{\partial \lambda}=\frac{1}{2} \frac{\left(2 L\left(\gamma+\frac{\delta+\lambda}{2}(1-\gamma)\right)+\rho \eta\right)^{2}(1-\delta)^{2}(1-\gamma)}{(1-\delta)\left(2 L\left(\gamma+\frac{\delta+\lambda}{2}(1-\gamma)\right)+\rho \eta\right)^{2}-(1+\delta) \rho \eta(1-2 h)\left(1-\frac{\delta+\lambda}{2}\right) L}
$$

This partial derivative is positive as long as $h>\frac{1}{2}$ and $\frac{\delta+\lambda}{2}<1$. 口 


\section{Appendix B}

Table 1

\begin{tabular}{|l|l|l|l|l|l|l|l|l|l|l|l|}
\hline$\sigma$ & $\alpha$ & $\tau$ & $\tau_{\text {tel }}$ & $\eta$ & $h$ & $L$ & $\rho$ & $\gamma$ & $g(\%)$ & $\partial V_{a} / \partial \gamma$ & $\partial V_{b} / \partial \gamma$ \\
\hline 3 & 0.8 & 1.2 & 1.2 & 10 & 0.8 & 2 & 0.05 & 0.7 & 6 & 6.7 & 1.75 \\
\hline 4 & & & & & & & & 0.64 & 2.8 & 4.35 & -0.03 \\
\hline & 0.5 & & & & & & & 0.7 & 1.9 & 2.5 & -0.25 \\
\hline & & 1.6 & & & & & & 0.59 & 5 & 12 & -0.45 \\
\hline & & & 1.6 & & & & & 0.71 & 5.58 & 8.51 & 4.71 \\
\hline & & & & 20 & & & & 0.84 & 1.41 & 3.27 & -1.44 \\
\hline & & & & & 0.6 & & & 0.57 & 5.6 & 7 & 1.52 \\
\hline & & & & & & 3 & & 0.64 & 10.6 & 9.67 & 4.53 \\
\hline & & & & & & & 0.03 & 0.62 & 7.3 & 17.7 & 9.1 \\
\hline
\end{tabular}




\section{Bibliography}

Baldwin R. and R. Forslid (2000), "The Core-Periphery model and endogenous growth : stabilizing and de-stabilizing integration", Economica, (67)3 pp. 307-324.

Baldwin R., Martin Ph. and G. Ottaviano (2001), "Global Income Divergence, Trade and Industrialisation : the geography of growth takeoffs", Journal of Economic Growth, 6, pp. 5-37.

Baldwin R., Forslid R., Martin Ph., Ottaviano G. and F. Robert-Nicoud (2003), Economic geography and public policy, Princeton University Press.

Caballero R. and A. Jaffe (1993), "Standing on the Giant's Shoulder : an assessment of knowledge spillovers and creative destruction in a model of economic growth", NBER Macroeconomics Annual, 8, pp. 15-73.

Cairncross F. (2001), The death of distance : how the communication revolution will change our lives, Harvard Business School Press, Cambridge.

Dixit A.K. and J.E. Stiglitz (1977), "Monopolistic competition and optimum product diversity", American Economic Review, 67, pp. 297-308.

Eaton J. and S. Kortum (1997), "International technology diffusion : theory and measurement", Working Paper 4931, NBER.

Englmann F.C. and U. Walz (1995), "Industrial centers and regional growth in the presence of local inputs", Journal of Regional Science, 35(1): pp. 3-27.

European Commission (1999), Sixth periodic report on the social and economic situation and development of the regions of the community, Bruxelles.

Feldman M. (1994), The Geography of Innovation, Kluwer Academic Publishers.

Gaspar J. and E. Glaeser (1998), "Information technology and the future of cities", Journal of Urban Economics, 43, pp. 136-156.

Grossman G. and E. Helpman (1991), Innovation and Growth in the Global Economy, Cambridge USA, MIT Press.

Jaffe A. (1989), "Real effects of academic research", American Economic Review, 79, pp. 957-70.

Krugman P. (1991), "Increasing returns and economic geography", Journal of Political Economy, 99, pp. 483-99.

Kuznets S. (1966), Modern economic growth, rate structure and spread, New Haven, Yale University Press.

Marshall A. (1926), Principles of Economics, 7 th ed., London, Macmillan.

Martin P. (1998), "Can regional policies affect growth and geography in Europe", World Economy, (21) 6, pp. 757-774. 
Martin P. (1999), "Public policies, regional inequalities and growth", Journal of Public Economics, pp. 73, 27.

Martin P. (2000), «A quoi servent les politiques régionales? », Économie Internationale, 81, pp. 3-19.

Martin P. and G. Ottaviano (1999), "Growing location : industry location in a model of endogeneous growth", European Economic Review, (43)2, pp. 281-302.

Martin P. and C.A. Rogers (1995), "Industrial location and public infrastructure", Journal of International Economics, 39, pp. 335-51.

Maurseth B. and B. Verspagen (1999), "Knowledge spillovers in Europe. A patent citation analysis", MERIT, Discussion Paper.

Quah D. (1996), Regional cohesion from local isolated actions : I. historical outcomes, mimeo, London School of Economic.

Quah D. (2000), "Internet cluster emergence", Working Paper 441, London School of Economic.

Riou S. (2002), "When transport infrastructures promote global growth and regional cohesion?", Discussion Paper, Creuset, University of SaintÉtienne.

Romer P. (1990), "Endogenous technological change", Journal of Political Economy, 98 (5), pp. 71-102.

Samuelson P. (1954), "The transfer problem and transport costs: analysis of effects of trade impediments", Economic Joumal, 64, pp. 264-89.

Venables A. (2001), Geography and international inequalities : the impact of new technologies, mimeo, London School of Economic.

Walz U. (1996), "Transport costs, intermediate goods and localized growth", Regional Science and Urban Economics, 26, pp. 671-695. 
